\title{
Thoughts and Countermeasures for Ningbo Constructing International Bulk Commodity Spot Transaction Market
}

\author{
Changqiu Wang \\ Commodity Business School, Ningbo Dahongying University, Ningbo, Zhejiang 315175, China
}

Keywords: Bulk Commodity, Spot Market, Internationalization, Ningbo

\begin{abstract}
With the development of the bulk commodity market, there are great market risks and problems emerging in endlessly. In this paper, it takes Ningbo as an example to construct the bulk commodity spot market, for the purpose of reducing the market risks and really realize the functions of spot service entity economy.
\end{abstract}

\section{Introduction}

As a developed port city in eastern China, Ningbo has vigorously outward-looking economy. The same as vivid characteristics of port economy, the bulk economy industrial development has developed rapidly and vigorously in Ningbo. Currently, Ningbo has already become an important center integrated of bulk commodity transaction, trade and logistics.

\section{Basic Conditions for Ningbo Constructing International Bulk Commodity Spot Transaction Market}

Natural Port Condition. Ningbo possesses natural ports, with the cargo throughput leaping into the front ranks of the world. As one of four deep-water harbors in China, Ningbo-Zhoushan Port is both a combined transportation hub and an importantly international airline, which possesses the natural advantages for constructing an international bulk commodity spot market. Ningbo has already become the major international transshipment and storage base of bulk commodities, including petroleum, liquid chemistry and mineral, and also the transshipment and storage base of coal, grain and wood.

Location of Trade and Geography. Due to the excellent geographical location conditions, Ningbo is the place of consumption, place of production and trade transshipment area, and also the clustering center of manufacturers, merchants and logistics. It is also the distribution node of bulk commodities of eastern China and inland China. Waterway transportation and international sales to foreign countries can be realized.

Foundation of Commercial Environment. Ningbo has a long history of engaging in business and the historical culture of "Justice and profit are regarded as equally important" and "Industry and commerce are of equal importance". Ningbo has broad marine economic hinterland, with consumption group of global bulk commodity spreading around. The regional commercial atmosphere is quite dense. Meanwhile, after years of reforming and practice, Ningbo has already formed a modern contract market, with quite sufficient activity and liquidity of market transactions.

Foundation of Political Environment. As the core area of Zhejiang marine economy national economy, China and Zhejiang have published policies to promote the construction of international bulk commodity transaction center in Ningbo, where has special areas supervised by the customs, including the bonded area, bonded logistics park, bonded port area and comprehensive bonded zone. These areas can support the bulk commodity transactions, thus Ningbo has unique political advantages of developing international transshipment, storage and manufacturing of bulk commodities.

Foundation of Information and Finance. Ningbo has developed information technology. Its smart industry and smart city have already stepped into the forefront of China. By taking internet, Internet of Things, telecommunication network, Radio and Television Network and wireless broadband networks as the foundation, Ningbo has formed a new urban development pattern mainly 
characterized by wisdom technology, industry and service. The plot program of "smart logistics" has created good conditions for Ningbo. As the international financial service center, Ningbo has already got 26 banks and insurance institutes, thus it has a good financial foundation.

\section{Major Problems Existing in the Bulk Commodity Transaction Market of Ningbo}

Construction and Enforcement of Regulations, Standards and Rules Lagging Behind Market Development. Currently, there is only one specification of the bulk commodity market, namely Bulk Stock Electronic Transaction Specification. This specification is merely an industrial standard, which does not possess the legal authority. In case of breach of contract, the breaching party cannot be punished, thus the degree of implementation is quite big. As the current market management system, although it simulates relevant mechanism of futures, it is short of regulations with legal effects to standardize and enforce, such as Administrative Regulations on Futures Trading, which leads the market supervision to have no law to abide by and results in law enforcement absence. It is quite easy to produce behaviors of market moral hazard and bad money driving out good money, which influences the stability of market.

Inconsistent Planning Core between the Province and City Hindering the Development of Market. Planning of governments at all levels and urban positioning have had impact on the construction of market. In the aspect of administrative planning, Ningbo is a sub-provincial municipality with independent planning status, whose development planning may not be limited by Zhejiang in some aspect. However, geological location and regional economic logistics of Ningbo still belong to Zhejiang. Such a relationship results in inconsistent planning core, which results in governmental regional coordination. Such as Ningbo and Zhoushan, which both belong to Yangtze River Delta, are both planned and constructed as the international bulk commodity transaction markets, which results in serious resource waste.

Supporting Infrastructure Influencing the Development of Market. Development of market needs necessary infrastructure. In the aspect of financing, information, logistics and concentrated transportation supporting, Ningbo takes the leading position, but the allocation is irrational. By taking collecting and distributing network of Ningbo as an example, it is mainly dominated by highway transportation now. Due to irrational allocation, non-smooth connection and quite low transporting efficiency, it cannot totally adjust to the requirements of bulk commodity. By taking Ningbo-Zhoushan Port as an example, the highway undertakes most part of container collecting and distributing volume, and also bulk and general cargo collecting and distributing volume, while the railway mostly undertakes the transportation of coal and iron ore, the collecting and distributing volume is quite small.

Poor Implementation of Clean-up and Rectification Influencing the Development of Market. The bulk commodity transaction market has a quite low access to the market. The risk undertaking and scale of operation obviously do not match, which results in a lot of problems and risks. Although China has released documents to clean and rectify those problems, due to local profits, such clean-up and rectification cannot be enforced powerfully. Due to ambiguous market management authority, there are no basis of punishing behaviors as manipulating the market or cheating clients, thus it cannot effectively prevent the occurrence of similar phenomenons. Meanwhile, the rectification may have influence the local GDP in the short run. Considering the economic benefits,the local supervision authority is not willing to actually enforce clean-up or rectification.

Talent Gap Influencing the Development of Market. With the development of Ningbo bulk commodity transaction market, the talent gap has been consistently enlarged. International bulk commodity transaction market have quite high demands of talents, which not only include professional and occupational talents, but also primary, middle and high-end talents. Currently, the shortcoming of talent gap has already influenced the development of market. Especially, Ningbo is extremely short of composite high-end talents who understand the financial and transaction rules, or apply the new technological methods, such as the Internet of Things. 


\section{New Thoughts of Ningbo Constructing International Bulk Commodity Spot Transaction Market}

Constructing Ecological, Integrated and Coordinated Spot Transaction Market. While constructing the market, it can take the ecological circle as the characteristics, so as to realize crisscrossed development. Modern commodity circulation embodies the platform economy, while the platform economy is the concept of ecological circle. Mostly, the traditional trade circulation is accomplished by a trading enterprise or logistics enterprise, which is some scattered link of the supply chain management. However, the spot transaction market just constructs a coordinated management in vertical and horizontal direction, opens up the supply chain covering the procurement, production and sales, and also unites the manufacturer, wholesaler, trader, financial institution and logistics enterprise into one, and then constitutes an ecological circle with related enterprises, so as to perform three-dimensional and comprehensive development.

Constructing the Spot Transaction Market with Circulation, Cloud Data and Low Cost. It should construct the market by taking the platform economy as the characteristics. The bulk commodity spot market transaction and B2C consumer goods platform economy have their own advantages and disadvantages. The consumer goods B2C platform economy has no logistics, but the bulk commodity B2B platform economy is lack of transaction. Therefore, it should specify that main-body of the platform is the field of circulation and encourage the dealers to carry out the platform. It can comprehensively master the key elements and information by establishing the cloud database, and also integrate related data of bulk commodities by setting up the bulk commodity big data application cloud platform. It should introduce data digging technology, so as to realize the shared service. By constructing the core management system of bulk commodity big data, it can gather basic data resources and general data interfaces of all professional transaction markets, so as to realize comprehensive connection. On that basis, it can fatherly extend to realize seamless connection between the core management system of Ningbo bulk commodity bid data and the internet and Internet of Things, further to jointly construct the smart bulk commodity spot transaction center.

\section{Countermeasures for Ningbo Constructing International Bulk Commodity Spot Transaction Market}

The Government Coordinating the Market Integration, Constructing the Comprehensive Leading Market. Bulk commodity transaction markets have scattered over Ningbo. Otherwise, it should establish market by regional industry, logistics or variety. Although the current 14 bulk commodity transaction markets of Ningbo have their own characteristics, all transaction markets should regulate the market behaviors based on their own rules. However, no market can lead the entire market pattern. The government should give the play of the coordinated and integrated function, integrate the market and platform by political guidance, preferential support and benefit share, construct one or two international bulk commodity transaction leading markets with unified rule, transaction pattern, platform and internet, so as to form influential power in China, or even in the world. According to the variety, Ningbo can integrate the current markets into several leading markets.

Innovative Ideas, Promoting the Coupling Development of Market and Industry. There is quite strong correlation between Ningbo industrial clustering and bulk commodity transaction market. In regions with quite good development of industrial clustering, it usually forms a bulk commodity transaction market based on that industry. Both of them present a form of coupling development. Such as Yuyao, the plastic industrial clustering has already formed the scale effect. Correspondingly, it has established Yuyao Plastic Electronic Trading Market. Zhenhai District has the petrochemical industrial clustering. Correspondingly, it has established Zhenhai Refining and Chemical Electronic Trading Market. Such coupling development of market and industry comes from one co-evolution effect, which is a series of co-evolution process including co-existence, innovation, economy and sharing effects. Moreover, it forms the result of common development. Therefore, it should possess innovative ideas while constructing the market and combine with the development stages and 
interactive conditions of both the market and industry from the perspective of co-evolution.

Improving the Foundation and Service Matching, Giving the Play of Clustering Effect including Logistics, Finance, Information. It should take the market demands as orientation, rely on the industrial chain' s core enterprises' resources and realize the synergetic development of the entire industry supply chain. It should improve the matching, reinforce the port construction, logistics matching, network construction and financial innovation, and then offer the overall, comprehensive and three-dimensional service integrated of transaction, logistics, finance and information. The spot commodity market should replace the function of intermediate traders, which introduce the manufacturing enterprises, circulating enterprises and consumers into the same environment. By the clustering effect, it can promote the industrial chain development of all industries.

Strengthening the Executive Force of Laws and Regulations, Standardizing the Market Speculation. When there was no perfect regulation and standard system, the market had risks of natural person and cash deposit, which affected the normal fluctuation of market price. Although all electronic trading markets have certain institutional systems, these system are mostly developed by themselves, which do not possess legal authority. Consequently, it must form rent seeking. Therefore, it should strengthen the enforcement of laws, regulations and rules, focus on examining behaviors violating Bulk Stock Electronic Transaction Specification and No.37 and No.38 documents of the State Council, devote greater efforts to punishing the illegal behaviors, reduce the market speculations and construct a stable market environment.

Reinforcing Market Supervision, Promoting Supervision by Supervision, Promoting Healthy Competition of Market. Targeted at the bulk commodity electronic transaction market, it can set up administrative supervision, statistical inspection, credit supervision and administrative law enforcement organizations, so as to form systems and layers. Organizations are composed of administrative departments and grass-roots institutions. Supervision and law enforcement subject should also be set up. It should strengthen the coordinating role of industrial association, give play of its role as bridge and bond, and also specify its function and promote the association to improve the operation mechanism. Currently, it is most important to develop industrial regulation and service requirement, set up industrial self-regulation and credit evaluation system,acceptance of complaint and mediation of disputes system. It should promote the construction of credit system.

Speeding up Professional Talents Cultivation and Social Training, Offering Intellectual Support. Shortage of professional talents is a shortcoming for Ningbo to construct an international bulk commodity transaction market, especially the high-qualified professional talents. The government should support universities and colleges to fatherly develop cultivation of professional talents majored in bulk commodity. Currently, it is most important to cultivate applied talents of bulk commodity electronic transaction market, including transaction, logistics, finance and e-commerce. Besides, it should make more investments on the cultivation of professional talents. Meanwhile, it should reinforce the introduction of high-level professional talents, and incorporate that into the talent introduction catalog of Ningbo Municipal Human Resources and Social Security Bureau. Meanwhile it should promote social training, set up bulk commodity social training service platform, carry out professional training and focus on training bulk commodity transaction analyst, strategist and senior professional manager. In addition, it should carry out social vocational qualification certificate, develop professional standards of bulk commodity transaction, so as to form a perfect bulk commodity professional standard system.

Giving the Coordinated Effect of Policy-industry-university-institute Alliance, Solving Key Problems. Development of the bulk commodity transaction market must rely on forces from all sectors of society, so as to play the role of synergistic effects. By integrating the resources of government, universities and colleges, industrial associations and bulk commodity enterprises, it should set up policy-industry-university-institute alliance and jointly explore the key problems existing in the bulk commodity transaction market. Enterprises can make professional analysis on the transaction quantity and volume of the bulk commodity transaction markets; the government can sort out development policies, market transition and service function; the associations can standardize the logistics platform, market operation, standard system and pattern innovation; colleges and 
universities can study the basic theory, market mechanism and pricing right of the bulk commodity transaction market; the scientific research institutions can study the variety development, market allocation, risk and financing. Through the coordination of alliance, it can carry out all-dimensional cooperation, realize the intelligent research to form relevant countermeasures and promote the development of bulk commodity transaction market.

\section{Acknowledgments}

This paper is the project entrusted by Ningbo Development and Reform Commission, the title is Research on Ningbo Bulk Commodity Transaction Market and Transaction platform Construction, the project No. 1120147016. It is also the soft science project of Ningbo, the title is On Industrial Clustering Innovations of Ningbo from the Perspective of International Trade Diversion. The project NO.:2012A10023.

\section{References}

[1] Lu Huijun. Explorations of the Construction of Ningbo Bulk Commodity Transaction Center. Journal of Party School of CPC Ningbo Municipal Committee, 2013,01:94-99.

[2] Hua Yongjian. Research on Government Intervention Mechanism of Bulk Commodity Market.Special Zone Economy, 2013,10:83-85.

[3] Li Shuyan. Explorations of Constructing Bulk Commodity International Trade and Logistics Center in Zhejiang. Macroeconomic Management,2013,10:81-82.

[4] Yang Danping, Yang Xiuxiu. Research on Development of Zhejiang Bulk Commodity Transaction Market. Journal of Ningbo University(Issue of Humanity and Social Science), 2013,06:95-100.

[5] An Jiuyi, Huang Quanming, Zhang Lin.Researches on Functions and Construction of Bulk Commodity Whole-course E-Commerce Logistics Information Platform. China Logistics \& Purchasing, 2013,24:66-67.

[6] Shen Lijuan, Liu Li.Positively Promoting the Construction of International Bulk Commodity Transaction Market. China Business Update,2013,10:56-57.

[7] Cai Jin. Development Trend and Innovations of Bulk Commodity Market. China Business and Market, 2013,12:6-9.2. 